\title{
An effect of IoT based Electronic Sow Feeder (ESF) on productivity of swine farms
}

\author{
Chunghan Kang ${ }^{1}$, Seoyoung Hwang ${ }^{2}$, Junghoon Moon ${ }^{3}$
}

\begin{tabular}{|c|c|}
\hline I N F O & A B S T R A C T \\
\hline Received & \\
\hline Accepted & This study aimed to investigate the effect of an electronic sow feeder (ESF) on the \\
\hline Available on-line & productivity of swine farms. The ESF is a specific component of the Internet of Things \\
\hline Responsible Editor: & $\begin{array}{l}\text { (IoT)-based swine production management systems, which are prevalently used by } \\
\text { swine farms. Though the effect of weight sorter adoption, another component of swine }\end{array}$ \\
\hline Keywords: & production management systems, have been clarified, the effect of ESF adoption has not \\
\hline Electronic sow feeder (ESF), & yet been understood. To accomplish the aim of study, data from 19 swine farms were \\
\hline Swine farm, Swine production & collected in Korea and a t-test was conducted. This study found that the ESF has a \\
\hline management systems & positive effect on decreasing the number of farrowing accidents, the mean days to re- \\
\hline & service, and increasing the average number of farrowing accidents. Though the findings \\
\hline & generally applied to other swine farms that use IoT-based swine production management \\
\hline & systems. Future research will extend these results while considering productivity data \\
\hline & and environmental data simultaneously. Examining the effects of other components of \\
\hline & $\begin{array}{l}\text { IoT-based production management systems is another possible direction to extend this } \\
\text { study. }\end{array}$ \\
\hline
\end{tabular}

\section{Introduction}

In Korea, swine production management systems were established and adopted in the livestock raising industry in the late 1990s (Jang et al. 2012). Though other fields of agricultural industry, such as horticulture industry, still aim to establish feasible production management systems to increase their productivity, swine production management systems are used by more than $43.5 \%$ of the swine farms (Park, Heo and Rim 2008). These days, the number of swine farms that adopt an Internet of Things (IoT)-based production management system is also increasing (Jang, Lee and Choe 2014). Internationally, IoT-based production management systems are prevalent in the livestock raising industry. According to Wheeler (2007), wireless and sensor networks, radio-frequency identification (RFID), and image processing technologies are already commercialized. Therefore, IoT-based production management systems applying these technologies have been briskly adopted in the livestock raising industry (Wheeler 2007).

Recently, researchers aimed to analyze gathered data from IoT-based swine production management systems, along with the large number of gathered data. For example, Lee, Song, and Choe (2014) investigated the effect of weight sorter adoption by comparing the carcass weight and backfat thickness before and after weight sorter adoption. The result showed the standard deviation of carcass weight and backfat thickness was decreased after weight sorter adoption (Lee, Song et al. 2014), which means the weight sorter increased the predictability of productivity.

\footnotetext{
1 First author

Seoul National University

chunghan@snu.ac.kr

2 Second author

Seoul National University

3 Corresponding author, third author

Seoul National University

moonj@snu.ac.kr
} 
A literature review found, however, that studies regarding the electronic sow feeder (ESF) have not yet been conducted. In this regard, this study aims to examine the effect of the ESF on the productivity of swine farms through comparing gathered data before and after ESF adoption.

In the following chapter, an explanation of the production process of swine farms and IoT-based swine production management systems is offered. Then, the data collection method is stated and the results of a statistical analysis to clarify the effect of ESF adoption on the productivity of swine farms are revealed. The implications of the findings of this study and a recommendation for future studies are also offered.

\section{Production Process of Swine Farms}

As shown in Figure 1, the production process of swine farms is complex. The manager of a swine farm should manage not only mother sows and piglets but also numerous kinds of pigpens. The manager of a swine farm should also make a decision at each stage of production.

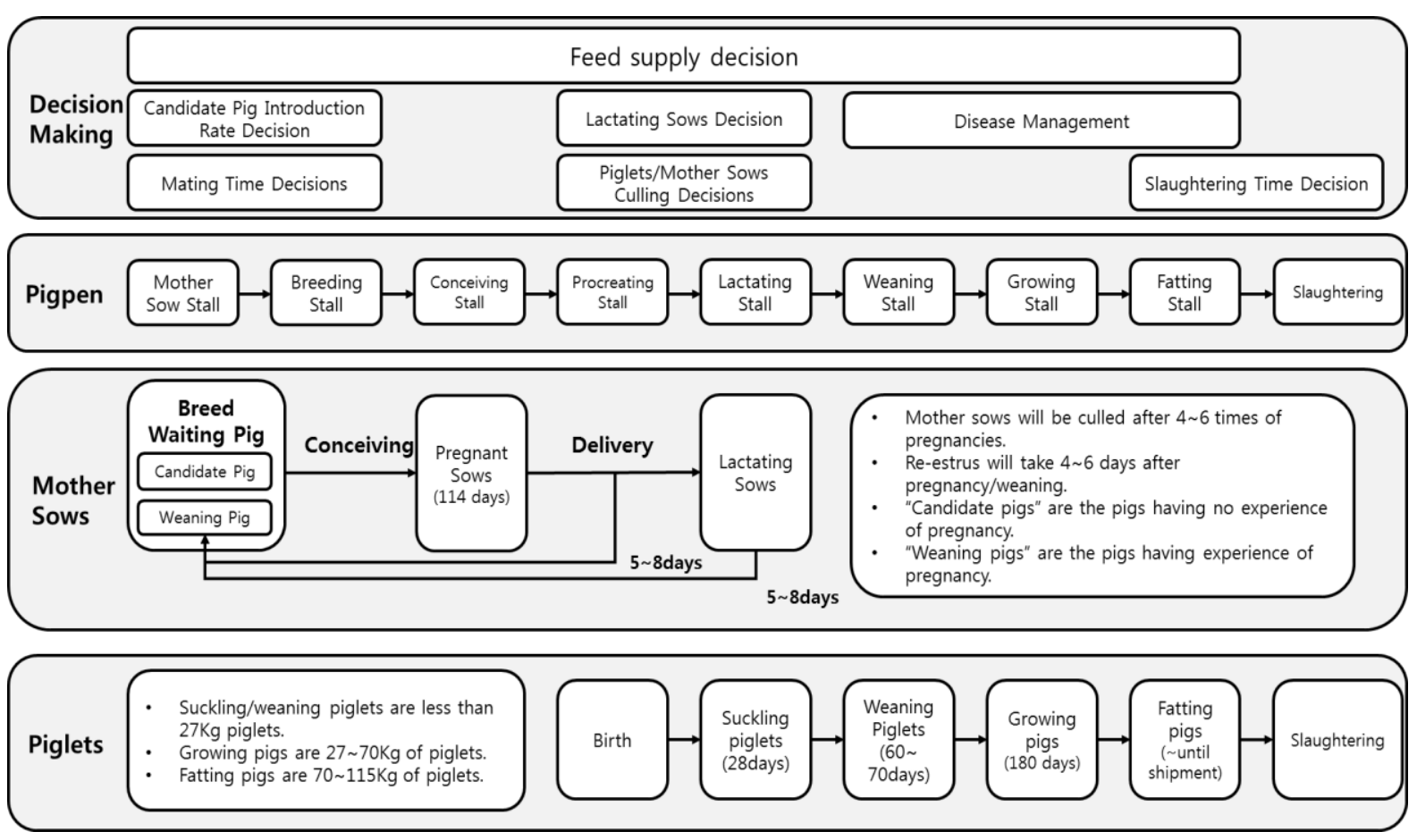

Figure 1. Production process of swine farms

The production process starts with introducing a candidate pig. Considering the mother sows should be culled after 4-6 pregnancies because of the decreased productivity, the swine farm manager should decide a candidate pig introduction rate adequately. Once a candidate pig or weaning pig is successfully impregnated in the breeding stall, it is moved to the conceiving stall. In the conceiving stall, pregnant sows stay for 114 days until they procreate piglets. After procreating in the procreating stall, the manager should choose the lactating sows among the mother sows that procreate piglets. The selected mother sows are sent to the lactating stall to feed the suckling piglets over 28 days and the rest are sent to the mother sow stall. The selected lactating sows are also sent back to the mother sow stall after 28 days. Re-estrus will take 5-8 days after the mother sows return to the mother sow stall.

The manager should identify the weak or ill piglets that are not profitable to cull right after the birth to minimize the cost of feeding piglets. The remaining piglets, the suckling piglets, are sent to the lactating stall and are fed by select lactating sows over 28 days. Once the suckling period is over, suckling piglets are sent to the weaning stall. The piglets in the weaning stall are called weaning piglets and they are fed in the weaning stall until they weigh $27 \mathrm{~kg}$, which normally takes 60 to 70 days. The 
weaning piglets whose weights are $27 \mathrm{~kg}$ are sent to the growing stall and they are called growing pigs. The growing pigs are sent to the fatting stall after three months if they weigh over $70 \mathrm{~kg}$. The pigs in the fatting stall are called fatting pigs. At this stage, the manager of the swine farm should determine the slaughtering date. This is an important decision because the meat quality and the physicochemical characteristics of the pork vary depending on the market weight of the fatting pig (Park et al. 2005).

It is also important for the manager of a swine farm to prevent and control infectious diseases, such as porcine reproductive and respiratory syndrome (PRRS), because infectious disease outbreaks, representatively PRRS, cause production and financial problems for swine farms (Lin et al. 2013). For example, the United States swine industry annually loses $\$ 560$ million owing to PRRS (Neumann et al. 2005).

IoT-based swine production management systems help swine farm managers in their decision making at each stage of production by monitoring and controlling the pig farm in real time (Jang, Lee and Choe 2014).

\section{IoT-based swine production management systems}

IoT-based swine production management systems consists of five components, including inside environment condition management systems, ESF, weight sorter, closed-circuit television (CCTV), and outside storage management systems (Jang, Lee and Choe 2014).

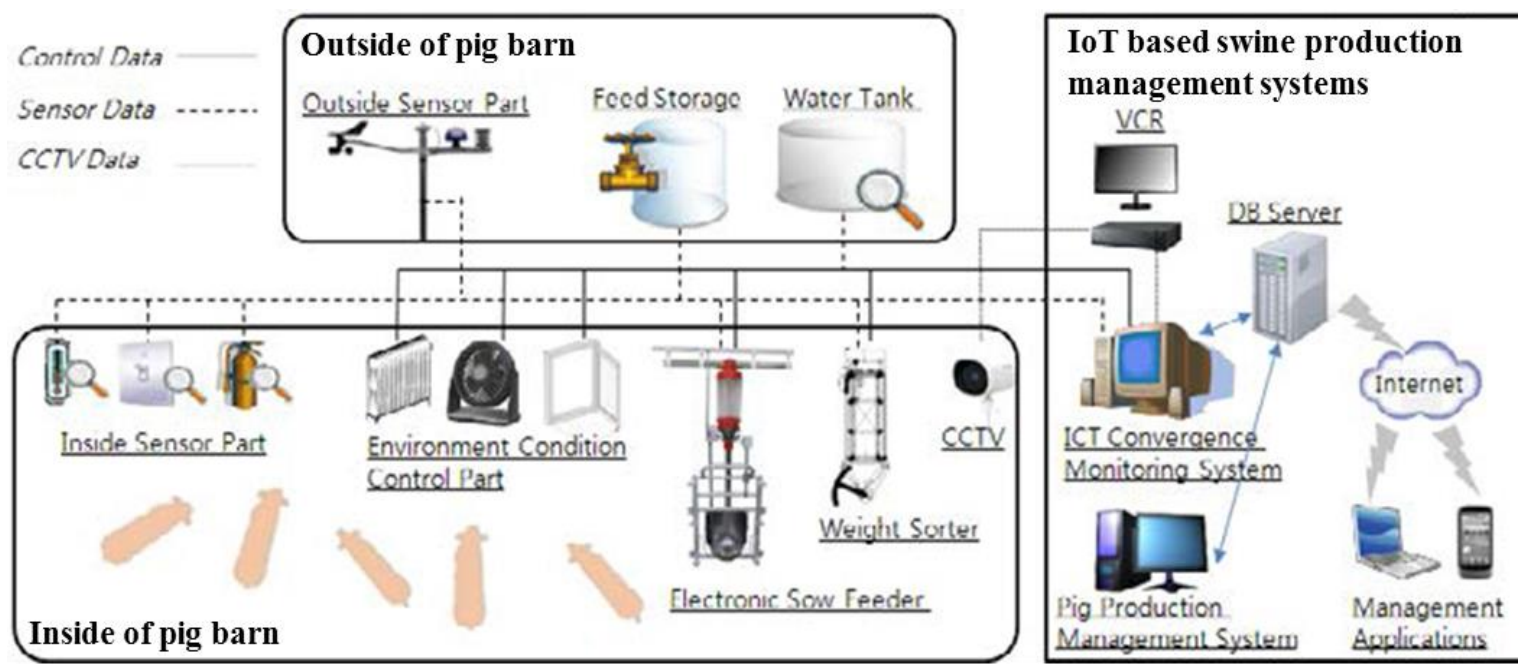

Figure 1. Diagram of IoT-based swine production management systems (Jang, Lee and Choe 2014)

In Figure 1, inside environment condition management systems are denoted as the inside sensor part, outside sensor part, and environment condition control part. The inside sensor part and outside sensor part sense the environment data, such as temperature and humidity. Based on the environment data gathered by the inside sensor part and outside sensor part, the environment condition control part automatically controls the environment of the pig barn. Radio frequency identification (RFID) tags are attached to the ears of the pigs in the pig barn. The ESF identifies each pig in the pig barn through sensing the attached RFID tags, controlling the amount of feed while considering the allocated daily amount of feed to each pigs. The weight sorter is installed in the growing stall and the fatting stall's middle corridor on the feeder. When pigs pass through the corridor, the weight sorter measures the weight of the pig and determines which gate should be opened. For example, if the growing pig weighing $60 \mathrm{~kg}$ in the growing stall passes through the weight sorter, the gate to the feeder will be opened. On the other hand, if the growing pig weighing over $70 \mathrm{~kg}$ in the growing stall passes through the weight sorter, the gate to the fatting stall will be opened. Through the CCTV and video cassette recorder (VCR), the manager of the pig farm can monitor inside of the pig barn. 
Each component of swine production management systems also gather various kinds of data, which are listed in Table 1.

Table 1. The kinds of gathered data by five components (Jang, Lee and Choe 2014)

\begin{tabular}{|c|c|c|c|}
\hline $\begin{array}{c}\text { Environment } \\
\text { condition } \\
\text { management }\end{array}$ & $\begin{array}{c}\text { Sensor Data } \\
\text { (inside and outside), } \\
\text { humidity } \\
\text { (inside and outside), } \\
\text { CO2, blackout, fire }\end{array}$ & Image Data & N/A \\
\hline $\begin{array}{c}\text { Electronic sow } \\
\text { feeder }\end{array}$ & contact, sow individual & N/A & N/A \\
\hline Weight sorter & weight, sow individual & N/A & N/A \\
\hline CCTV & N/A & $\begin{array}{c}\text { photo, video, infrared } \\
\text { and thermal camera }\end{array}$ & $\begin{array}{c}\text { inside of pig barn (pig's } \\
\text { crying) }\end{array}$ \\
\hline $\begin{array}{c}\text { Feed storage, } \\
\text { Water tank }\end{array}$ & milk quantity, remaining & & \\
\hline
\end{tabular}

The gathered data listed in Table 1 are stored on the data base (DB) server in Figure 1. The manager of the pig farm can utilize gathered data with the pig production management system and mobile management applications.

\section{Data Collection}

To accomplish the aim of study, data was collected from 19 swine farms in Korea that adopted a new IoT-based production management system, namely Pig Plan. The ESF is a specific component of the entire production management system, which means adopting the ESF is optional. Considering the seasonality of swine farms' productivity, at least one year's worth of data is required before and after ESF adoption. In addition, mating frequency should not be statistically different before and after the adoption. Of the 19 farms' data, five farms' data were adequate to analyze the effect of ESF adoption properly.

For measuring the swine farm's productivity, three indices were chosen; the number of farrowing accidents, the mean days of re-service, and farrowing rates, which are widely used in the swine raising industry to evaluate the swines' productivity. The number of farrowing accident is the summation of the number of mother sows that fail to get pregnant after breeding and that miscarry. Mean days to reservice means the average number of days to re-estrus of the mother sows after procreating or lactating. The farrowing rate is defined as the ratio between the number of mother sows that succeed in procreating piglets and the number of mother sows that successfully become pregnant. Thus, these three indices are directly linked to the productivity of the swine farms. A t-test was conducted on the mean of three indices before and after ESF adoption to clarify the effect of ESFs on the productivity of swine frams.

\section{Statistical Analysis and Results}

The data of five farms included in the analysis were aggregated and a t-test was conducted. The results of the t-test are listed in Table 2, showing the average number of farrowing accidents was significantly decreased (mean before adoption $=21.89$, mean after adoption $=17.85, \mathrm{t}=2.7112, \mathrm{p}<0.05$ ) but the mean days to re-service (mean before adoption $=7.28$, mean after adoption $=7.82, \mathrm{t}=-.6682$, 
$\mathrm{p}>0.05$ ) and the average farrowing rates (mean before adoption $=82.25$, mean after adoption $=82.08, \mathrm{t}$ $=.0884, \mathrm{p}>0.05)$ were not influenced by the ESF.

Table 2. The results of t-test (aggregate case)

\begin{tabular}{|c|c|c|c|c|c|c|c|c|c|}
\hline & \multicolumn{3}{|c|}{$\begin{array}{c}\text { Average number of } \\
\text { farrowing accidents }\end{array}$} & \multicolumn{2}{c|}{ Mean days to re-service } & \multicolumn{3}{c|}{ Average farrowing rate } \\
\cline { 2 - 9 } & $\begin{array}{c}\text { Before } \\
\text { adoption }\end{array}$ & $\begin{array}{c}\text { After } \\
\text { adoption }\end{array}$ & t-value & $\begin{array}{c}\text { Before } \\
\text { adoption }\end{array}$ & $\begin{array}{c}\text { After } \\
\text { adoption }\end{array}$ & t-value & $\begin{array}{c}\text { Before } \\
\text { adoption }\end{array}$ & $\begin{array}{c}\text { After } \\
\text { adoption }\end{array}$ & t-value \\
\hline $\begin{array}{c}\text { Total } \\
\text { Means }\end{array}$ & $\mathbf{2 1 . 8 9}$ & $\mathbf{1 7 . 8 5}$ & $\mathbf{2 . 7 1 1 2} *$ & $\mathbf{7 . 2 8}$ & $\mathbf{7 . 8 2}$ & $\mathbf{- . 6 6 8 2}$ & $\mathbf{8 2 . 2 5}$ & $\mathbf{8 2 . 0 8}$ & $\mathbf{. 0 8 8 4}$ \\
\hline
\end{tabular}

$* \mathrm{p}<.05$

To investigate the differences in the effects of the ESF across the farms, a t-test was conducted five times on the each of the five farms' data separately. According to the results in Table 3, farm A, which had the best performance after the adoption of ESFs, showed significant decreases in the average number of farrowing accidents (mean before adoption $=26.44$, mean after adoption $=16.25, \mathrm{t}=2.5227$, $\mathrm{p}<0.05$ ) and the mean days to re-service (mean before adoption $=9.45$, mean after adoption $=6.05, \mathrm{t}=$ $2.2099, \mathrm{p}<0.05$ ), as well as significant increases in the average farrowing rates (mean before adoption $=76.76$, mean after adoption $=86.99, \mathrm{t}=-3.5205, \mathrm{p}<0.05)$. Farm $\mathrm{B}$ showed significant decreases in mean days to re-service (mean before adoption $=8.32$, mean after adoption $=6.87, \mathrm{t}=3.0692, \mathrm{p}<0.05$ ) and farm $\mathrm{C}$ showed significant decreases in the average number of farrowing accidents (mean before adoption $=22.06$, mean after adoption $=12.82, \mathrm{t}=2.5155, \mathrm{p}<0.05)$ and increases in the average farrowing rates (mean before adoption $=88.92$, mean after adoption $=93.34, \mathrm{t}=-2.5471, \mathrm{p}<0.05$ ). Alternatively, farm D and E showed insignificant effects of ESF adoption.

Table 3. The results of the t-test

\begin{tabular}{|c|c|c|c|c|c|c|c|c|c|}
\hline & \multicolumn{3}{|c|}{$\begin{array}{l}\text { Average number of } \\
\text { farrowing accident }\end{array}$} & \multicolumn{3}{|c|}{ Mean days to re-service } & \multicolumn{3}{|c|}{ Average farrowing rate } \\
\hline & $\begin{array}{c}\text { Before } \\
\text { adoption }\end{array}$ & $\begin{array}{c}\text { After } \\
\text { adoption }\end{array}$ & t-value & $\begin{array}{l}\text { Before } \\
\text { adoption }\end{array}$ & $\begin{array}{c}\text { After } \\
\text { adoption }\end{array}$ & t-value & $\begin{array}{l}\text { Before } \\
\text { adoption }\end{array}$ & $\begin{array}{c}\text { After } \\
\text { adoption }\end{array}$ & t-value \\
\hline Farm A & 26.44 & 16.25 & $2.5227 *$ & 9.45 & 6.05 & $2.2099 *$ & 76.76 & 86.99 & $3.5205^{*}$ \\
\hline Farm B & 12.29 & 16.39 & -2.0446 & 8.32 & 6.87 & $3.0692 *$ & 90.14 & 86.49 & 2.4396 \\
\hline Farm C & 22.06 & 12.82 & $2.5155 *$ & 5.49 & 5.71 & -.9697 & 88.92 & 93.34 & $-2.5471 *$ \\
\hline Farm D & 8.06 & 9.88 & -1.2166 & 5.56 & 6.4 & -.9094 & 77.72 & 87.07 & -1.2898 \\
\hline Farm E & 24.71 & 24.89 & -.182 & 6.51 & 7.25 & -1.7919 & 86.16 & 83.25 & .7826 \\
\hline
\end{tabular}

$* \mathrm{p}<.05$

According to the results, the ESF is helpful to decrease the average number of farrowing accidents and mean days to re-service, and ESF is also helpful to increase average farrowing rate, which are directly related to the productivity of swine farms. Thus, IoT-based production management systems, especially with ESFs, have a positive effect on the productivity of swine farms.

\section{Conclusion}

To satisfy farmers' increased demands for scientific and automated production management systems, academic efforts should be made to identify IoT-based production management systems that generate positive effects on productivity. In this regard, this study contributes to establishing a feasible 
and generalizable method to identify the effect of IoT-based production management systems on swine farm productivity.

Though the results of this study are limited to the selected swine farms in Korea, the method of this study is easily applied to other swine farms that have adopted IoT-based production management systems. Future research will extend the results of this study in two ways. First, other factors that have an effect on the productivity of farms (e.g., environmental data) must be considered simultaneously with the effects of the ESF. Second, examining the effects of other components of IoT-based production management systems, such as environment condition management systems, is also needed.

\section{Acknowledgement}

This research was supported by the MSIP (Ministry of Science, ICT and Future Planning), Korea, under the C-ITRC (Convergence Information Technology Research Center) (IITP-2015-H8601-151007) supervised by the IITP (Institute for Information and Communications Technology Promotion)

\section{References}

Jang, IH, Lee, SY and Choe, YC 2014, 'ICT convergence integrated management system for a pig farm: Integrated data usages and values', ASIA LIFE SCIENCES, supplement. 10, pp. 139-154.

Jang, IH, Park, SH, Choi, YC and Kim, YH 2012, 'Cases of Eco-Friendly Pigsty and Hog Feeding and Management Based on u-IT Information Systems', Agribusiness and Information Management, vol. 4, no. 2, p. 42.

Lee, SY, Song, CH and Choe, YC 2014, 'The Convergence of ICT and Automatic Sorting System: A Quantitative Performance Analysis', Advanced Science and Technology Letters, vol. 49 (Soft Tech 2014), pp. $229-235$.

Lin, H, Wang, C, Liu, P and Holtkamp, DJ 2013, 'Construction of disease risk scoring systems using logistic group lasso: application to porcine reproductive and respiratory syndrome survey data', Journal of Applied Statistics, vol. 40, no. 4, pp. 736-746. doi: 10.1080/02664763.2012.752449

Neumann, EJ, Kliebenstein, JB, Johnson, CD, Mabry, JW, Bush, EJ, Seitzinger, AH, Green, AL and Zimmerman, JJ 2005, 'Assessment of the economic impact of porcine reproductive and respiratory syndrome on swine production in the United States', Journal of the American Veterinary Medical Association, vol. 227, no. 3, pp. 385-392. doi: $10.2460 /$ javma.2005.227.385

Park, Y-J, Heo, P-S and Rim, M-H 2008, 'Measurement of a customer satisfaction index for improvement of mobile RFID services in Korea', ETRI journal, vol. 30, no. 5, pp. 634-643. doi: 10.4218/etrij.08.1308.0059

Wheeler, A 2007, 'Commercial applications of wireless sensor networks using ZigBee', Communications Magazine, IEEE, vol. 45, no. 4, pp. 70-77. doi: $10.1109 /$ mcom.2007.343615

J. C. Park, Y. H. Kim, H. J. Jung, B. Y. Park, J. I. Lee and H. K. Moon 2005, 'Comparison of Meat Quality and Physicohemical Characteristics of Port between Korean Native Black Pigs (KNBP) and Landrace by Market Weight', Journal of Animal Science and Technology, vol. 47, no. 1, pp. 91-98. doi: 10.5187/jast.2005.47.1.091 